\title{
Summarizing activity limitations in children with chronic illnesses living in the community: a measurement study of scales using supplemented interRAl items
}

\author{
Charles D Phillips ${ }^{1,4^{*}+}$, Ashweeta Patnaik ${ }^{2 \dagger}$, Darcy K Moudouni ${ }^{1 \dagger}$, Emily Naiser ${ }^{2 \dagger}$, James A Dyer ${ }^{2 \dagger}$,
} Catherine Hawes $^{1+}$, Constance J Fournier ${ }^{3 \dagger}$, Thomas R Miller ${ }^{1+}$ and Timothy R Elliott ${ }^{3,4 \dagger}$

\begin{abstract}
Background: To test the validity and reliability of scales intended to measure activity limitations faced by children with chronic illnesses living in the community. The scales were based on information provided by caregivers to service program personnel almost exclusively trained as social workers. The items used to measure activity limitations were interRAl items supplemented so that they were more applicable to activity limitations in children with chronic illnesses. In addition, these analyses may shed light on the possibility of gathering functional information that can span the life course as well as spanning different care settings.

Methods: Analyses included testing the internal consistency, predictive, concurrent, discriminant and construct validity of two activity limitation scales. The scales were developed using assessment data gathered in the United States of America (USA) from over 2,700 assessments of children aged 4 to 20 receiving Medicaid Early and Periodic Screening, Diagnostic and Treatment (EPSDT) services, specifically Personal Care Services to assist children in overcoming activity limitations. The Medicaid program in the USA pays for health care services provided to children in low-income households. Data were collected in a single, large state in the southwestern USA in late 2008 and early 2009. A similar sample of children was assessed in 2010, and the analyses were replicated using this sample.
\end{abstract}

Results: The two scales exhibited excellent internal consistency. Evidence on the concurrent, predictive, discriminant, and construct validity of the proposed scales was strong. Quite importantly, scale scores were not correlated with (confounded with) a child's developmental stage or age. The results for these scales and items were consistent across the two independent samples.

Conclusions: Unpaid caregivers, usually parents, can provide assessors lacking either medical or nursing training with reliable and valid information on the activity limitations of children. One can summarize these data in scales that are both internally consistent and valid. Researchers and clinicians can use supplemented interRAl items to provide guidance for professionals and programs serving children, as well as older persons. This research emphasizes the importance of developing medical information systems that allow one to integrate information not only across care settings but also across an individual's life course.

\footnotetext{
* Correspondence: phillipscd@srph.tamhsc.edu

+ Contributed equally

'Program on Disability, Aging, and Long-Term Care Policy, Texas A\&M Health

Science Center, School of Rural Public Health, College Station, Texas, USA

Full list of author information is available at the end of the article
} 


\section{Background}

In 2008, over 31 million children living in low-income households in the United States of America (USA) were eligible to receive services from Medicaid's Early and Periodic Screening, Diagnostic, and Treatment (EPSDT) program [1]. Medicaid in the USA uses a combination of state and federal funds to pay for health services provided to low-income families, persons with disabilities, and older persons needing long-term care. In 2009, almost 3 million children in the large, southwestern state of Texas were eligible for EPSDT services [2]. Health care for these children accounted for Medicaid expenditures of approximately US $\$ 1.8$ billion [3]. The bulk of these expenditures were for the periodic examinations required for all EPSDT participants [4].

Among those in Texas receiving EPSDT services, a small but important proportion are children with chronic health problems who receive care at home. Many of these children receive assistance with activity limitations through Medicaid Personal Care Services (PCS). The average child in the Medicaid program in Texas in 2010 accumulated annual Medicaid expenditures totaling US $\$ 1,866$; expenditures for children receiving PCS in their homes averaged almost 20 times that amount (US\$36,314). For all children receiving home-based Medicaid services, the average annual expenditure for those home-based services was US $\$ 3,499$; for those receiving PCS, the average annual bill for home-based services was US\$23,469 [5].

Using the terminology of the International Classification of Function (ICF) as our frame of reference, PCS are provided by home care personnel to help individuals whose health conditions or impairments create activity limitations [6-9]. Since the 1970s, the Texas Medicaid program has, through a variety of mechanisms, provided assistance with activities of daily living (ADLs) and instrumental activities of daily living (IADLs) to low-income children whose conditions result in activity limitations. PCS are provided solely to compensate for an activity limitation deriving from a health condition. In addition, unlike some other programs, in order to receive services the adult(s) responsible for the child must be unable to provide the needed assistance $[10,11]$.

The link between need and services is sometimes unclear, especially for children. When one observes an older person with an activity limitation, one assumes the etiology of the limitation is a health condition or impairment. An older man who could once safely bathe himself but now cannot do so is obviously in need of assistance. He may have this limitation because of an impairment (e.g., limited range of motion) created by a condition (e.g., osteoarthritis).
In contrast, a child in the EPSDT program who cannot safely bathe herself may, or may not, be suffering from a limitation due to a condition or impairment. If the child is 3 years old, an inability to bathe safely and independently is expected because of the child's developmental stage or age. Bathing a child of 3 is an activity carried out by all parents or adults responsible for a child. But, a child of 3 with Lobstein disease (brittle bone disease) may require 2-person assistance to be bathed safely or the bath may take much longer than a bath for other children of the same age. This additional care burden associated with a medical condition or impairment would make a child of any age eligible for Medicaid PCS to assist with bathing. A child of 16 with severe intellectual disability (ID) may be eligible for PCS assistance in bathing, while a child of 16 with mild ID may be perfectly capable of bathing safely and not qualify for PCS.

Other assessment tools contain the elements of the ICF model, but they are not specifically tailored to determining the need for services in the home [12]. The WeeFIM ${ }^{\circledR}$ can be used to screen for developmental delay in children 6 months to 8 years old [13]. The Pediatric Evaluation of Disabilities Inventory (PEDI) can be used to evaluate the level of disability for children 6 months to $71 / 2$ years old [14]. For these instruments, the determination of the presence of a limitation is based on a comparison of a child's ability with the ability of children with no known impairments and no evidence of developmental delay. These "norming" samples are, however, often of limited size and exhibit very limited diversity in race, ethnicity, and economic status [15-17].

Other instruments have different limitations. The Functional Status Scale (FSS) is designed for use with severely impaired children after hospitalization, used for a small number of activity limitations (motor function and eating), and is designed for use by highly-trained health professionals $[18,19]$. Other scales, like the Gross Motor Function Scale (GMFS), focus only on one aspect of function, limitations in motor function [20].

The popular Adaptive Behavior Assessment System, Second Edition (ABAS-II), in contrast assesses needs for all ages, and the validation samples are relatively large [21]. However, the coding for items in the system runs from zero (is not able to perform the task) to 3 (always or almost always performs the task). Such a scoring system does little to assist service providers in knowing how much assistance a client may need over the course of a week. Again, the focus is largely on identifying individuals with problems (e.g., those with scores two standard deviations below the norm for their group), not on determining how much assistance the child needs due to activity limitations. 
This research presents the results of an effort to tailor an assessment tool to determine a child's need for home care services to address activity limitations related to their health conditions or impairments. The effort focused on the use of caregivers' reports of a child's activity limitations to an individual with no special medical, therapy, or nursing training. We based the assessment on instruments used with adults and modified items on those instruments so that they were appropriate for children. We specifically designed the instruments to recognize the reality of home care for children. In such situations, program staff and health professionals are dependent on reports from informal caregivers for much of their information about a child's limitations and strengths.

The primary goal of the effort was for EPSDT case managers in Texas to gather reliable and valid information on a child's activity limitations in order to develop a service plan for the child. Here we present information related to a secondary goal of the effort - producing reliable and valid scales summarizing a child's healthrelated activity limitations.

A secondary goal of the effort, intertwined with the instrument development and scaling activities, was determining how well assessment items originally developed for use with older persons could serve as the basis for items and scales focused on children's activity limitations resulting from a health problem. This issue is of some importance for medical information systems. Most concerns about integrating medical information have related to integrating and standardizing data across care settings. Another issue, which receives less attention, is integrating medical information across a person's life course. When different information systems and measurement strategies are used for children, adults, and older persons, this reduces a clinician's ability to provide the continuity of care that can positively affect both individual and population health.

\section{Methods}

\section{Participants}

Since September 2007, under the leadership of the Texas Health and Human Services Commission (HHSC), case managers in the Texas Department of State Health Services (DSHS) have assessed children seeking or receiving EPSDT services to determine their need for PCS. In September 2008, case managers began using new assessment tools. Two multi-dimensional assessment instruments were developed and tested for reliability and face validity prior to their implementation. The Personal Care Assessment Form 0-3 (PCAF 0-3) was used to assess the PCS need of children under 4 years old. The Personal Care Assessment Form 4-20 (PCAF 4-20) was used to assess all other children seeking or using PCS as a part of EPSDT services.
For the first 6 months of the PCAF's use, case managers submitted all completed PCAFs to the research team. Nine of the 11 state health regions provided PCAF data from September 2008 through February 2009. Implementation was delayed in 2 regions because of the demands placed on DSHS staff by hurricane damage. These regions supplied data from December 2008 through March 2009. These paper forms were reviewed and entered into an electronic database.

The research team received 3,068 assessments. A few assessments (8) could not be used due to missing data, and 99 assessments involved no authorization for PCS services. The PCAF 0-3 data included 201 children. In Texas, 5,493 children with chronic illnesses were participating in the PCS program in April, 2009 when all data collection ended. Our sample represents just over onehalf of the population of children receiving PCS. Ninetythree percent of those assessed were over 3 years of age. This research is restricted to the 2,760 children from 4 to 20 years old.

The assessment instruments were also used by Medicaid managed care organizations (MCOs), but these organizations did not provide assessment data to the State or the research team. Thus, the study population was restricted to those children in the Medicaid FeeFor-Service market or children in the Medicaid Primary Care Case Management Program. This restriction does no harm to the study. This research investigates functional measurement; the goals do not include providing population estimates for the entire Medicaid population.

PCAFs were completed in a home visit in which the primary caregiver and the child were present. The assessor was a case manager employed by the Texas Department of State Health Services. A few case managers were nurses, but licensed social workers with a master's degree in social work (MSW) comprised the vast majority of case managers. The assessment was completed by using the instrument to query the caregiver, informal observation of the child, and questioning the child (if the child was capable of responding).

An almost identical data collection was completed in 2010, after minor changes unrelated to the measures of activity limitations were made in the instrument. This effort lasted four months, and PCAF data were collected in early 2010 on a sample of 2,642 children in the EPSDT program across Texas. All research activities in the project were approved by the Institutional Review Board of Texas A\&M University.

\section{Measurement}

The PCAF was purpose-built for determining children's needs for PCS. It was largely based on items, or variants of items, included in the Minimum Data Set for Nursing Home Resident Assessment (now the interRAI-LTCF ${ }^{\circ}$ ) 
[22] or the Minimum Data Set for Home Care ${ }^{\odot}$ (now the interRAI-HC ${ }^{\odot}$ ) [23]. Both instruments were developed for use with frail older persons and have proven reliability and validity when used with older populations [24-26]. For an older population, the interRAI ADLs exhibit excellent reliability and scale very well [27]. The research team modified items, response sets, and examples on these assessment tools for adults so that they were appropriate for use with children.

The PCAF relies heavily on input from the primary caregiver, usually a family member. In order to receive Medicaid Personal Care Services, a child in the EPSDT program must have a primary caregiver who provides assistance with activity limitations. PCS services can be provided only when the caregivers, or caregivers, have some barrier to providing needed assistance.

The PCAF included items on the assistance provided over the last 7 days in bed mobility, positioning while upright, eating, transfer, mobility inside the dwelling, mobility outside, toilet use, dressing, personal hygiene, and bathing. Initial testing of these items with children receiving EPSDT services resulted in weighted kappas for the individual ADL items that ranged from 0.55 to 0.74, with an average of 0.64 [28]. The kappas indicated that all 10 items exhibited moderate (4 items) or substantial (6 items) reliability [29]. The reliability test involved 264 dual assessments.

While some instruments use a 3-day look-back window, for children the research team decided that a 7day period was more appropriate. Often parents and other informal caregivers are at work or school during weekdays, and the child is usually at school during weekdays. Weekends are the times that informal caregivers get a more detailed picture of the child's needs. In support of this assumption, our analyses of the 2009 data indicate that formal care time varied little across the weekdays, but formal care hours changed significantly on Saturday and Sunday.

With the exception of bathing, the ADL items used the same response set:

- total independence;

- set-up help only;

- monitoring/supervision/cueing/redirection with rare hands-on assistance;

- limited assistance, regular hands-on assistance with rare weight-bearing assistance;

- extensive assistance, some involvement by the participant but regular weight-bearing help from a caregiver; or

- total dependence, the activity was performed by the caregiver with no or minimal assistance from the child.
The codes for bathing also ranged from 0 to 5 , but the response set differed slightly from the other ADLs.

Like all interRAI activity limitation items, the caregiver indicated the assistance provided with each ADL. For children, the assessor also determined, through discussions with the caregiver and observation, whether a child's activity limitation was affected by her or his health conditions. Those children whose performance in an activity was not affected by a condition were classified as independent in our analyses. Those whose ability to perform an activity was affected by a health condition or impairment kept the assistance score originally assigned for that activity.

Thus, a child of 4 might be coded as totally dependent in dressing. However, if this need was not driven by a health condition, but simply by developmental stage or age, then in our analyses, the child's was scored as being independent. Children with an activity limitation that derived from an underlying impairment or condition received the score that reflected how much care they received with that activity (e.g., limited assistance, total dependence). In each ADL, the child's score depends on the impact of their health conditions or impairments on their activity limitations. The score is not a function of the child's developmental stage or age.

For illustrative purposes, this research focuses on 2 activity limitation scales. An additive scale for all 10 activity scores $(0-50)$ is the first. The second is an additive scale $(0-10)$ reflecting the number of activities in which the child regularly received at least hands-on assistance (i.e., limited assistance, extensive assistance, or total dependence). The research team developed both scales; case managers had no ADL summary measures available to them when they determined the child's service needs.

The chosen measurement strategy demands that caregivers made judgments about whether a child's activity limitations derive from a condition or impairment. We investigate the validity and reliability of activity limitation scales derived from the items that demand this judgment. In doing so, we provide one test of the reliability and validity of caregivers' judgments about the etiology of children's activity limitations.

Other PCAF items were used in exploring the usefulness of this measurement strategy and the scales summarizing a child's limitations. These items included information on the child's age, cognitive status, and performance in IADLs, and the number of hours of PCS authorized following assessment. A complete copy of the PCAF 4-20 is available at http://pcaf.tamu.edu.

\section{Analyses}

The analyses focused on the distributional and psychometric properties of our two scales. We tested the 
internal consistency of the scales for different portions of the sample. The predictive, discriminant, concurrent, and construct validity of the scales were tested using other items in the PCAF [30-32]. The tests were initially performed using the 2008-2009 database. The 20082009 results were then validated using assessments in the 2010 database for children not included in the earlier wave of assessments.

\section{Results}

Table 1 presents descriptive statistics for our study participants. The majority was male, and sample members were relatively evenly spread across the age span covered by the sample. Almost two-thirds of these children faced multiple challenges, with 64 percent presenting with both medical and mental health conditions. Almost one-half of them had an intellectual disability of some type; one-quarter had attention deficit hyperactivity disorder (ADHD); over one-quarter had a seizure disorder. Four out of 5 study participants had significant difficulty following multi-step instructions.

The participants' activity limitations appear in Table 2 . Sample members were least likely to need hands-on assistance with bed mobility and most likely to need it with bathing. The degree to which activities were affected by the child's conditions and the degree to which they required hands-on assistance break the activities into 3 groups. Very Complex activities (toilet use, personal hygiene, dressing, bathing), most likely to require personal care, involved multiple steps and

Table 1 Descriptive data for Children with Chronic Illnesses Living in Low-Income Households $(\mathbf{n}=\mathbf{2 , 7 5 5 )}$

\begin{tabular}{|c|c|c|}
\hline Variables & Categories & $\begin{array}{l}\text { Prevalence } \\
\text { (\%) }\end{array}$ \\
\hline Gender & Male & 57.7 \\
\hline \multirow[t]{4}{*}{ Age group } & 4-8 years old & 29.5 \\
\hline & 9-12 years old & 24.4 \\
\hline & 13-16 years old & 21.1 \\
\hline & 17-20 year old & 25.0 \\
\hline \multirow[t]{3}{*}{ Child's current qualifying condition(s) } & Medical only & 22.0 \\
\hline & Psychiatric/developmental/behavioral only & 14.0 \\
\hline & Both types of conditions & 64.0 \\
\hline \multirow{15}{*}{$\begin{array}{l}\text { Most Commonly Reported Diagnoses Or Conditions (Prevalence 10\% or } \\
\text { greater) }\end{array}$} & Epilepsy/chronic seizure disorder & 28.8 \\
\hline & Asthma/respiratory disorder & 24.8 \\
\hline & Cerebral palsy & 24.4 \\
\hline & Paraplegia/tetraplegia/quadriplegia & 11.2 \\
\hline & Intellectual disability & 48.4 \\
\hline & $\mathrm{ADHD}$ & 25.7 \\
\hline & Autistic disorder & 16.7 \\
\hline & Mood disorder & 14.1 \\
\hline & Anxiety disorder & 13.6 \\
\hline & Disruptive behavior disorder & 10.6 \\
\hline & Restricted range of motion & 35.3 \\
\hline & Pain & 17.1 \\
\hline & Bedbound & 16.2 \\
\hline & Contractures & 14.9 \\
\hline & Falls related to condition & 13.5 \\
\hline Procedural memory & $\begin{array}{l}\text { Unable to follow most or all multi-step } \\
\text { instructions }\end{array}$ & 82.3 \\
\hline Receptive Communication & Sometimes, rarely, or never understands & 54.8 \\
\hline Bladder control & Frequent, usually, or always incontinent & 47.5 \\
\hline Control of bowels & Frequent, usually, or always incontinent & 43.5 \\
\hline \multirow[t]{3}{*}{ Urgent medical care in 30 days prior to assessment } & Physician visit & 11.1 \\
\hline & Emergency department & 8.0 \\
\hline & Hospital admission & 5.3 \\
\hline
\end{tabular}


Table 2 Activity Limitations among Children with Chronic Illnesses Living in Low-Income Households $(\mathbf{n}=\mathbf{2 , 7 5 5 )}$

\begin{tabular}{|c|c|c|}
\hline Activity & \% Whose Performance Was Affected by Their Condition(s) & $\%$ Who Needed Hands-on Assistance \\
\hline Bed mobility & 30.1 & 27.8 \\
\hline Positioning & 32.9 & 30.3 \\
\hline Locomotion inside & 38.4 & 33.6 \\
\hline Transfer & 40.8 & 38.2 \\
\hline Locomotion outside & 46.6 & 40.7 \\
\hline Eating & 59.2 & 42.4 \\
\hline Toilet use & 83.0 & 72.2 \\
\hline Personal hygiene & 91.9 & 79.0 \\
\hline Dressing & 92.1 & 79.6 \\
\hline Bathing & 94.6 & 82.8 \\
\hline
\end{tabular}

needed fine motor control. Less Complex activities, least likely to require assistance, involved a limited number of ordered steps or the use of large muscle groups (bed mobility, locomotion inside, and positioning). Between these two groups are activities that call for gross motor control but do involve a number of ordered tasks; these are simply classified as Complex (locomotion outside, transfer) [33].

Table 3 presents information on the distribution of the scales and some of their psychometric properties. The two scales were relatively well distributed with little skewness, but their distributions were a bit flattened at their high point (negative kurtosis). The coefficient of variation for both scales was roughly 0.60 . The average score on the Additive Scale was 25, while the Hands-on Scale indicated that the average sample participant needed hands-on assistance with 5 of 10 activities. The inter-quartile range for the Additive Scale was from 1340. On the Hands-on Scale, the inter-quartile index indicated that one-quarter of the sample needed handson assistance in fewer than 3 activities, while another quarter received hands-on assistance in 9 or 10 activities. Both scales had excellent internal consistency $(\alpha \geq$ 0.90). This strong internal consistency carried over to subgroups in the sample, specifically for both genders and within each of our 4 age groups. The analyses of internal consistency also focused on the degree to which the scale held together for three different sub-populations - those children with medical problems alone, those with only psychiatric, developmental or behavioral problems, and finally, the majority, who exhibited both classes of problems.

For the purposes of establishing an important aspect of discriminant validity, we analyzed the relationship between scale scores and age. For those interested in screening for developmental delay, the correlation of a screening tool score and age should be strong, as it is with the WeeFIM ${ }^{\circledR}$ [13]. For a measure of activity limitations to determine service needs, the measure should not correlate with age. We are seeking measures of a child's service needs that are not intertwined with a child's age or level of development.

Though other aspects of discriminant validity might be considered, the lack of significant correlations between the 2 scales and the age of the children in the sample provides crucial evidence of an important aspect of the scales' discriminant validity. The lack of a correlation between age and the scales implies that the supplemented interRAI items are measuring activity limitations that derive from health conditions or impairments, not a child's age or developmental stage.

For concurrent validity, one hopes to correlate the scales under scrutiny with established scales measuring the same construct. However, in the project team's field data collection, which was dependent on the staff and resources of the DSHS, the use of multiple items to measure the same construct (activity limitations) was not feasible. Instead, the measures we must use to test for one aspect of concurrent validity are other PCAF items that should be related to a child's functional status and any ADL scale. In this instance, we correlated the 2 ADL scales with an IADL scale (a scale summarizing a child's needs for assistance in 7 instrumental activities of daily living) and a binary item indicating whether the child needed 2-person assistance with any activity. As should be the case, both scales exhibit significant positive correlations with these alternative measures of the severity of activity limitations. The scales also exhibited a strong positive correlation with our 5-item, additive cognitive function scale composed of items related to short-term memory, long-term memory, decision-making, receptive communication, and expressive communication.

The predictive validity of our activity limitation scales was tested by correlating the scale values with the number of hours of weekly PCS authorized by the DSHS case manager following the assessment. These correlation coefficients were well in the range $(0.40-0.50)$ of 
Table 3 ADL or Activity Limitation Scales based on PCAF Activity Limitation Measures

\begin{tabular}{|c|c|c|c|c|}
\hline Scale Properties & $\begin{array}{c}\text { Development } \\
\text { Sample, 2009 } \\
(n=2760)\end{array}$ & $\begin{array}{c}\text { Development } \\
\text { Sample, 2009 } \\
(\mathrm{n}=2760)\end{array}$ & $\begin{array}{c}\text { Validation Sample, } \\
2010 \\
(\mathrm{n}=1765) \\
\end{array}$ & $\begin{array}{c}\text { Validation Sample, } \\
2010 \\
(n=1765)\end{array}$ \\
\hline & $\begin{array}{c}\text { HC-PEDS } \\
\text { ADL Limitations Scale }\end{array}$ & $\begin{array}{c}\text { HC-PEDS } \\
\text { Hands-on Needs } \\
\text { Scale } \\
\end{array}$ & $\begin{array}{c}\text { HC-PEDS } \\
\text { ADL Limitations } \\
\text { Scale }\end{array}$ & $\begin{array}{c}\text { HC-PEDS } \\
\text { Hands-on Needs } \\
\text { Scale }\end{array}$ \\
\hline \multicolumn{5}{|l|}{ Distribution } \\
\hline Mean & 24.9 & 5.3 & 23.0 & 4.9 \\
\hline St. Deviation & 15.3 & 3.3 & 14.3 & 3.1 \\
\hline Skewness & 0.4 & 0.1 & 0.6 & 0.2 \\
\hline Kurtosis & -1.1 & -1.1 & -0.8 & -0.9 \\
\hline Median & 21 & 5 & 19 & 4 \\
\hline Inter-quartile range & $13-40$ & $3-9$ & $12-33$ & $3-8$ \\
\hline Range & $0-50$ & $0-10$ & $0-50$ & $0-10$ \\
\hline \multicolumn{5}{|l|}{$\begin{array}{l}\text { Internal Consistency (unstandardized Cronbach's } \\
\text { alpha) }\end{array}$} \\
\hline Full sample & 0.93 & 0.90 & 0.93 & 0.89 \\
\hline Ages 4-8 & 0.92 & 0.88 & 0.91 & 0.86 \\
\hline Ages 9-12 & 0.93 & 0.90 & 0.93 & 0.89 \\
\hline Ages 13-16 & 0.94 & 0.91 & 0.93 & 0.90 \\
\hline Ages 17-20 & 0.93 & 0.90 & 0.94 & 0.88 \\
\hline Male & 0.93 & 0.90 & 0.93 & 0.89 \\
\hline Female & 0.93 & 0.90 & 0.92 & 0.89 \\
\hline Medical conditions only & 0.93 & 0.89 & 0.92 & 0.88 \\
\hline $\begin{array}{l}\text { Psychiatric, development or behavioral conditions } \\
\text { only }\end{array}$ & 0.79 & 0.76 & 0.77 & 0.73 \\
\hline $\begin{array}{l}\text { Both medical and psychiatric, development or } \\
\text { behavioral conditions. }\end{array}$ & 0.93 & 0.90 & 0.93 & 0.89 \\
\hline \multicolumn{5}{|l|}{ Discriminant Validity (Pearson's r) } \\
\hline Age & $\begin{array}{c}-0.016 \\
(p=0.39)\end{array}$ & $\begin{array}{c}-0.012 \\
(p=0.50)\end{array}$ & $\begin{array}{l}-0.0174 \\
(p=0.46)\end{array}$ & $\begin{array}{c}-0.025 \\
(p=0.28)\end{array}$ \\
\hline \multicolumn{5}{|l|}{ Concurrent Validity (Pearson's r) } \\
\hline $\begin{array}{l}\text { Additive IADL scale } \\
\text { (2009 sample } \alpha=0.88 ; 2010 \text { sample } \alpha=0.87 \text { ) }\end{array}$ & 0.329 & 0.304 & 0.320 & 0.292 \\
\hline 2-Person Assistance w/an ADL & 0.464 & 0.444 & 0.538 & 0.504 \\
\hline $\begin{array}{l}\text { Cognitive Scale } \\
\text { (2009 sample } \alpha=0.82 ; 2010 \text { sample } \alpha=0.82 \text { ) }\end{array}$ & 0.355 & 0.309 & 0.368 & 0.315 \\
\hline \multicolumn{5}{|l|}{ Predictive Validity (Pearson's r) } \\
\hline PCS hours authorized & 0.455 & 0.435 & 0.436 & 0.424 \\
\hline \multicolumn{5}{|l|}{ Construct Validity $\left(\mathrm{R}^{2}\right)$} \\
\hline OLS Model & 0.65 & 0.59 & 0.71 & 0.64 \\
\hline
\end{tabular}

correlations observed when evaluating the correlation of activity limitations with service provision for other populations $[34,35]$.

Construct validity demands that a scale fit into a conceptual framework or theoretical schema [32]. While we lack some explicit deductive theory into which we can place scales measuring a child's activity limitations, a conceptual framework is available. Within the ICF framework, activity limitations should, in part, be a function of diseases and disorders and their effects on bodily structures or function [7]. To put it in other terms, a scale measuring activity limitations should serve as a statement of the totality of the effects of health conditions or impairments on a child's activity limitations [36]. With chronic illnesses, one frequently observes specific conditions that create an array of impairments and activity limitations. These conditions create a cascade of problems. 
For example, paralysis can be the result of a variety of diagnoses. No matter the condition, paralysis can reduce respiratory function, impair cardiovascular function, or facilitate skin breakdown. These impairments can result, respectively, in recurrent lower respiratory infections, dyspnea, or soft tissue infections. In instances where a child has multiple conditions or impairments, one's ability to attribute limitations to any specific health challenge is difficult. So a scale reflecting activity limitations serves as a convenient summary of the totality of the effects of a person's heath conditions and impairments on their ability to perform basic life skills.

To test the construct validity of the 2 scales, we used the scales as dependent variables in ordinary least squares (OLS) regressions, using health conditions and impairments as independent variables. These problems included the child's:

- cognitive function - a scale based on items related to short-term memory, long-term memory, interpretive communication, executive function, and procedural memory.

- problems with urinary, bowel or night-time continence - an indicator of any continence problem

- medical co-morbidities and impairments - a binary indicator for the presence of a variety of condition or impairments that might affect ADL function.

- type of condition that created the need for assistance - behavioral, psychiatric, or developmental conditions alone; medical conditions only; or both medical and psychological conditions.

All these data came from the PCAF assessment (see http://pcaf.tamu.edu).

The $\mathrm{R}^{2}$ for those models varied from 0.71 to 0.59 . These scales summarizing limitations are driven, as one would hope, largely by the child's conditions and impairments.

As columns three and four indicate, the results obtained in our analyses of the 2008-2009 data were duplicated when the same analyses were performed on a similar database of children assessed for the PCS program for the first time in early 2010. The results in the first two columns of Table 3 are not idiosyncratic.

\section{Discussion}

One goal of this effort was to produce measures of the health-related activity limitations for children facing chronic illness. We constructed these indicators and scales so that they were consistent with the ICF framework and consistent with interRAI instruments coming into greater use in the United States and internationally. The items also met the requirement that any activity limitation results from a medical condition or impairment.

The scales developed from the individual items related to ADL performance had very good internal consistency. This was true for the population as a whole and for a number of sub-groups in the population. The scales also demonstrated good to excellent concurrent, predictive, and construct validity. The results demonstrate that low-income caregivers reporting to state program staff with no medical or nursing training can provide valid and reliable data on children's activity limitations and strengths. All these results were consistent across both the developmental and the validation samples, indicating that the scales may have some measure of external validity.

In addition, the two scales exhibited an important aspect of discriminant validity. A child's score on these scales was independent of the child's age. A strong correlation with age is a laudatory quality in an instrument designed to screen for developmental delay [13]. However, when seeking to measure activity limitations that derive from health conditions or impairments, such a correlation is unfortunate. It negates one's ability to make the important claim that the measured limitations result from the child's health, not the child's age or developmental stage. Finally, this approach to measuring activity limitations required neither reference to potentially questionable and culturally-biased population norms nor an assessment by highly-trained, highly-paid medical or nursing professionals, which can be in short supply in some settings.

The findings in this research also imply that while the size and proportions of the body change, bathing for a 10 year old or a 70 year old involves the same mechanics. In both instances, we can measure the assistance provided on the same metric. Measures with the same logic and response sets can be valid and reliable when used to assess activity limitations in a child or an older person. This indicates that clinicians and researchers may be able to measure functionality with almost identical assessment tools and discuss activity limitations in a common language throughout an individual's life course. The results imply that not only can we have a "common language" for discussing activity limitations across care setting, but we may also be able to use that language across a person's lifespan.

This research, of course, has limitations. These data come from a single state. They are restricted to those children receiving Medicaid services outside managed care organizations. All participants came from lowincome households, and many were members of ethnic or racial minorities. If the underlying dynamics of caregiving and functional loss differ in other populations or 
settings, then these results may have limited external validity. Also, the tests for concurrent validity in this research were limited by the available data. Additional research to fill these gaps would seem to be the next logical steps in this area of research.

\section{Conclusions}

These results clearly reinforce the idea that home care is a partnership between providers and families. Our main source of information on a child's activity limitations was an unpaid caregiver, usually a family member. This person usually has the most detailed information about a child's limitations [36]. Even for the most impaired children living in the community, family and informal caregivers provide the bulk of the care [37]. This research indicates that information provided by family caregivers to non-medical professionals forms a firm foundation for the construction of a personalized treatment plan aimed at ameliorating the effects of a child's health problems on their physical activity limitations $[36,38]$. Such comprehensive sources of health status collected regularly can also have salutary effects of a population's health. For example, considerable evidence suggests the use of such a comprehensive regularized assessment process improved the quality of care provided to nursing home residents in the USA [22,27].

Our efforts also have implications for those committed to unified health information systems [39]. Much of the discussion of information integration has focused on integrating information across care settings. This research focused on a different issue - the possibility of integrating health status information across an individual's life course. Our results indicate that the measures of activity limitations that work well with the elderly can also, with appropriate supplementation and minor revision, provide reliable and valid information on the needs of children. Within a specific cultural matrix (e.g., industrialized western societies), activities of daily living are essentially the same for children and adults. Such a system is important for all persons seeking health care, but it is of crucial importance for the provision of high quality care to individuals with lifelong chronic illnesses.

\section{Acknowledgements}

This research was supported, in part, by funds from Medicaid Division of the Texas Health and Human Service Commission. The authors acknowledge with gratitude the assistance of Marianna Zolondek, Ryan Keyser, and Billy Millwee of the Commission.

\section{Author details}

${ }^{1}$ Program on Disability, Aging, and Long-Term Care Policy, Texas A\&M Health Science Center, School of Rural Public Health, College Station, Texas, USA ${ }^{2}$ Public Policy Research Institute, Texas A\&M University, College Station, Texas, USA. ${ }^{3}$ Counseling Psychology Department, Texas A\&M University, College Station, Texas, USA. ${ }^{4}$ Child \& Adolescent Health Research Laboratory, Texas A\&M University, College Station, Texas, USA.

\section{Authors' contributions}

CDP, EN, JAD, CH, CJF, and TRE developed the instrumentation and project plan. JAD and EN supervised the data collection. AP cleaned the data. All authors were involved in planning the paper and analyses of the results. AP, DKM, and TRM performed the analyses. CDP wrote the first draft. All authors commented on and approved the final draft of the paper.

\section{Competing interests}

The authors declare that they have no competing interests.

Received: 21 April 2011 Accepted: 23 January 2012

Published: 23 January 2012

\section{References}

1. Centers for Medicare \& Medicaid Services: State Agency Responsibilities: 1995 to 2008 National Data. Baltimore, Centers for Medicare \& Medicaid Services; 2009.

2. Centers for Medicare \& Medicaid Services: State Agency Responsibilities: 1995 to 2008 State Data. Baltimore, Centers for Medicare \& Medicaid Services; 2009.

3. Henderson T: Agency's Appropriation Year 2010 Monthly Financial Report. Austin, Texas Health and Human Services Commission; 2009.

4. Texas Health and Human Services Commission: Texas Medicaid and CHIP in Perspective. Austin, Texas Health and Human Services Commission; 2009.

5. Miller TR, Phillips CD, Patnaik A, Dyer JA, Fournier CJ, Elliott TR, Johnson J, Naiser E: Medicaid expenditures for children in Texas receiving Medicaid personal services, September 2008 - August 2009. College Station, Texas A\&M Health Science Center 2010.

6. World Health Organization: International Classification of Functioning, Disability and Health. Geneva, World Health Organization; 2001.

7. Lollar D: Rehabilitation Psychology and Public Health: Commonalities, Barriers, and Bridges. Rehabilitation Psychology 2008, 53:122-127.

8. Lollar D, Crews J: Redefining the role of public health in disability. Annu Rev Public Health 2003, 24:195-208.

9. Simeonsson RJ, Leonardi M, Lollar D, Bjorck-Akesson E, Hollenweger J, Martinuzzi A: Applying the International Classification of Functioning, Disability and Health (ICF) to Measure Childhood Disability. Disabil Rehabil 2003, 25:602-610.

10. Kitchener M, Ng T, Willmott M, Harrington C: The Texas Medicaid State Plan Personal Care Services Program. San Francisco, Center for Personal Assistance Services serial online; 2006

11. LeBlanc AJ, Tonner MC, Harrington C: State Medicaid Programs Offering Personal Care Services. Health Care Financ Rev 2001, 22:155-174.

12. Msall ME: Measuring Functional Skills in Preschool Children at Risk for Neurodevelopmental Disabilities. Ment Retard Dev Disabil Res Rev 2005, 11:263-273.

13. Msall ME, DiGaudio K, Rogers BT, LaForest S, Catanzano NL, Campbell J, Wilczenski F, Duffy LC: The Functional Independence Measure for Children (WeeFIM): Conceptual Basis and Pilot Use in Children with Developmental Disabilities. Clin Pediatr 1994, 33:421.

14. Feldman AB, Haley SM, Coryell J: Concurrent and Construct Validity of the Pediatric Evaluation of Disability Inventory. Phys Ther 1990, 70:602.

15. Liu M, Toikawa H, Seki M, Domen K, Chino N: Functional Independence Measure for Children (WeeFIM): A Preliminary Study in Nondisabled Japanese Children. Am J Phys Med Rehabil 1998, 77:36.

16. Msall ME, DiGaudio K, Duffy LC, LaForest S, Braun S, Granger CV: WeeFIM: Normative Sample of an Instrument for Tracking Functional Independence in children. Clin Pediat 1994, 33:431.

17. Wong V, Wong S, Chan K, Wong W: Functional independence measure (WeeFIM) for Chinese children: Hong Kong cohort. Pediatrics 2002, 109: e36.

18. Odetola F: Assessing the Functional Status of Hospitalized Children. Pediatrics 2009, 124:e163.

19. Pollack MM, Holubkov R, Glass P, Dean JM, Meert KL, Zimmerman J, Anand KJS, Carcillo J, Newth CJL, Harrison R, Willson DF, Nicholson C: Functional Status Scale: New Pediatric Outcome Measure. Pediatrics 2009, 124:e18.

20. Linder-Lucht $M$, Othmer $V$, Walther $M, V r y ~ J$, Michaelis $U$, Stein $S$, Weissenmayer $\mathrm{H}$, Korinthenburg R, Mall V: Validation of the Gross Motor 
Function Measure for Use in Children and Adolescents with Traumatic Brain Injuries. Pediatrics 2007, 120:e880.

21. Harrison P, Oakland T: Adaptive Behavior Assessment System. The Psychological Corporation; 2 2003, (ABAS-II).

22. Hawes $\mathrm{CH}$, Morris JN, Phillips CD, Fries BE, Murphy K, Mor V: Development of the Nursing Home Resident Assessment Instrument in the USA. Age Ageing 1997, 26:19.

23. Morris JN, Fries BE, Steel K, Ikegami N, Bernabei R, Carpenter Gl, Gilgen R, Hirdes JP, Topinková E: Comprehensive Clinical Assessment in Community Setting: Applicability of the MDS-HC. J Am Geriatr Soc 1997, 45:1017.

24. Hawes C, Morris JN, Phillips CD, Mor V, Fries BE, Nonemaker S: Reliability Estimates for the Minimum Data Set for Nursing Home Resident Assessment and Care Screening (MDS). Gerontologist 1995, 35:172.

25. Morris JN, Hawes C, Fries BE, Phillips CD, Mor V, Katz S, Murphy K, Drugovich ML, Friedlob AS: Designing the National Resident Assessment Instrument for Nursing Homes. Gerontologist 1990, 30:293.

26. Morris JN, Fries BE, Morris SA: Scaling ADLs within the MDS. J Gerontol A Biol Sci Med Sci 1999, 54:M546.

27. Phillips CD, Morris JN, Hawes C, Fries BE, Mor V, Nennstiel M, lannacchione V: Association of the Resident Assessment Instrument (RAl) with Changes in Function, Cognition, and Psychosocial Status. J Am Geriatr Soc 1997, 45:986.

28. Phillips CD, Hawes C, Dyer JA, Elliott T, Fournier C, Halperin L, Shaw M, Patnaik A, Chen M: Reliability Testing of the Personal Care Assessment Forms (PCAFs): A report prepared for the Texas Health and Human Services Commission. College Station, Texas A\&M Health Science Center; 2010.

29. Landis J, Koch G: The measurement of observer agreement for categorical data. Biometrics 1977, 33:159-174.

30. Carmines E, Zeller R: Reliability and validity assessment. Thousand Oaks: Sage Publications, Inc; 1979.

31. Cronbach $L$, Meehl P: Construct validity in psychological tests. Psychol Bull 1955, , 52: 281-302.

32. DeVellis R: Scale development: Theory and applications Thousand Oaks: Sage Publications, Inc; 2003.

33. Phillips CD, Patnaik A, Dyer JA, Naiser E, Hawes C, Fournier CJ, Elliott TR: Reliability and the Measurement of Activity Limitations (ADLS) for Children with Special Health Care Needs(CSHCN) Living in the Community. Disabil Rehabil .

34. Bjorkgren MA, Fries BE, Shugarman L: A RUG-III case-mix system for home care. Can J Aging 2000, 19:106-125.

35. Phillips CD, Dyer JA, Janousek V, Halperin L, Hawes C: Providing Appropriate Services to Individuals in the Community: A Preliminary Case-mix Model for Allocating Personal Care Services. J Health Hum Serv Adm 2008, 30:378-401.

36. Fournier CJ, Davis MJ, Patnaik A, Elliott TR, Dyer JA, Jasek EE, Phillips CD: Modeling Caregivers' Perceptions of Children's Need for Formal Care; Physical Function, Intellectual Disability, and Behavior. Disabil Health $J$ 2010, 3:213-221.

37. National Alliance for Caregiving: Caregivers of Children: A Focused Look at those Caring for a Child with Special Needs under the Age of 18. Bethesda, The MetLife Foundation; 2009.

38. Elliott TR, Phillips CD, Patnaik A, Naiser E, Booth EA, Fournier CJ, Miller TR, Moudouni DM, Hawes C, Dyer JA: Medicaid Personal Care Services and Caregivers' Reports of Children's Health: The Dynamics of a Relationship. Health Serv Res.

39. Gray LC, Berg K, Fries BE, Henrard J, Hirdes JP, Steel K, Morris JN: Sharing Clinical Information Across Care Settings: The Birth of an Integrated Assessment System. BMC Health Serv Res 2009, 9:71.

\section{Pre-publication history}

The pre-publication history for this paper can be accessed here: http://www.biomedcentral.com/1472-6963/12/19/prepub

doi:10.1186/1472-6963-12-19

Cite this article as: Phillips et al: Summarizing activity limitations in children with chronic illnesses living in the community: a measurement study of scales using supplemented interRAI items. BMC Health Services Research 2012 12:19.

\section{Submit your next manuscript to BioMed Central and take full advantage of:}

- Convenient online submission

- Thorough peer review

- No space constraints or color figure charges

- Immediate publication on acceptance

- Inclusion in PubMed, CAS, Scopus and Google Scholar

- Research which is freely available for redistribution

Submit your manuscript at www.biomedcentral.com/submit
Biomed Central 